\title{
A memória histórica de Getúlio Vargas e o Palácio do Catete ${ }^{1}$
}

\author{
Celso Pereira de Sá \\ Ricardo Vieiralves de Castro \\ Universidade do Estado do Rio de Janeiro \\ Renato Cesar Möller \\ Faculdade Salesiana Maria Auxiliadora \\ Juliana Aieta Perez. \\ Universidade do Estado do Rio de Janeiro
}

\begin{abstract}
Resumo
O artigo trata da memória histórica de Getulio Vargas (1883-1954) - que governou o país de 1930 a 1945 e de 1951 a 1954 -, em sua estreita associação com o Palácio do Catete, no Rio de Janeiro, sede da Presidência da República naquele período. Tal memória foi investigada em termos das representações sociais de Getúlio manifestadas por 410 visitantes de uma exposição realizada no Palácio - hoje, Museu da República - em homenagem ao cinqüentenário da sua morte. Os resultados, obtidos a partir das respostas a uma tarefa de associação livre e a um questionário expedito, evidenciam que a memória construída a propósito da trajetória histórica de Vargas é complexa e controvertida, mas tende nitidamente para o pólo positivo, visto que predominam as avaliações de que Getúlio fez mais coisas boas do que ruins e de que merece ser lembrado como "pai dos pobres" e como "maior estadista do Brasil".
\end{abstract}

Palavras-chave: getúlio vargas, memória social, memória histórica, representação social, palácio do catete

\begin{abstract}
The historical memory of Getúlio Vargas and the Catete Palace. The article deals with the historical memory of Getúlio Vargas (1883-1954) - who governed Brazil from 1930 to 1945 and from 1951 to 1954 -, in its close association to the Catete Palace, in Rio de Janeiro, which was the Republic Presidency's seat during that period. Such a memory was investigated in terms of the social representations about Getúlio which were manifested by 410 visitors to an exhibition held in the Palace - Republic Museum, nowadays - in honor to the fiftieth anniversary of his death. Results, which were obtained from responses to a free association task and to a concise questionnaire, evidence that the memory which was built about the historical trajectory of Vargas is a complex and controversial one, but it tends sharply for the positive pole, since the evaluations that Getúlio did more good than bad things and that he deserves to be remembered as "father of the poor people" and as "Brazil's greatest statesman" prevail.
\end{abstract}

Keywords: getúlio vargas; social memory; historical memory; social representation; catete palace

$\mathrm{N}$ o decorrer da última década, a psicologia social retomou o estudo da memória, por meio não só da releitura da obra de um dos pioneiros da disciplina (Bartlett, 1932/1995), mas também da apropriação de contribuições - desde as igualmente pioneiras (Halbwachs, 1925/1994, 1950/1997) às mais recentes - de outras disciplinas do domínio humano e social.

No Brasil, após a recuperação desses autores por E. Bosi (1979), observaram-se iniciativas relacionadas à história oral, às histórias de vida ou memórias autobiográficas e ao resgate de documentos históricos de interesse psicológico. A vertente na qual se insere o presente trabalho busca conjugar esforços de elaboração conceitual e de articulação teórica (Sá, 2005, 2007, no prelo) com um privilégio concedido ao estudo da memória de épocas e fatos históricos nacionais (Castro, 2005; Castro, Sá, Möller, \& Bezerra, 2005; Möller, Sá, \& Bezerra, 2004; Naiff, Sá, \& Möller, 2004; Oliveira, Lewin, \& Sá, 2004; Sá \& Castro, 2005; Sá, Castro, Oliveira, Teixeira, Trezzi, \& Vetere, 2005, Sá, Castro, Oliveira, Teixeira, Trezzi, \& Carvalho, 2005; Sá \& Oliveira, 2002; Sá, Oliveira, \& Prado, 2004; Sá \& Vala, 2000).

Nessa linha de investigações, há que se levar obrigatoriamente em consideração as relações entre história e memória, cuja discussão crítica tem ido proporcionada por historiadores como J. Le Goff(1988) e P. Nora (1997). Deve-se, em especial, ao último deles a noção de lugares de memória, status atribuído a espaços arquitetônicos, monumentos, obras de arte e museus, livros e bibliotecas ou qualquer outro tipo de registro do passado, quando 
passam a ter sobre eles concentrados esforços de construção de uma memória social.

É uma transformação como esta que se acredita ter ocorrido com o Palácio do Catete, no Rio de Janeiro, então sede do governo brasileiro, a partir do mesmo dia - 24 de agosto de 1954 - em que o presidente Getúlio Vargas, aos 71 anos de idade, aí se suicidou. Responderam pelo processo de sua constituição em um lugar de memória, ao longo dos últimos cinqüenta anos, a rememoração freqüente do episódio, bem como a estreita associação do lugar em si às representações que o povo brasileiro construiu sobre o homem que o governou durante quase vinte anos.

Numa classificação proposta por Sá (2005), o conjunto de tais representações constitui uma memória histórica documental, conceito que toma emprestada a noção histórica de documento, mas flexibiliza-a além do que seria possivelmente aceitável pelos historiadores, de modo a incluir todos os registros de que as pessoas e grupos se valem para lembrar o passado, mesmo que não o tenham testemunhado. Além disso, segundo a perspectiva psicossocial assumida pelo autor, os documentos como tais não se configuram, apenas pela disponibilidade, como uma memória. O que ele chama de memória histórica documental só vem a se constituir quando os documentos são mobilizados - visitados, lidos, apreciados ou simplesmente referidos - por pessoas e grupos sociais concretos.

Tal mobilização psicossocial em torno de um documento que pode ser um espaço, uma construção, um monumento, uma pintura, um livro, um filme, etc - corresponde nitidamente ao que Nora (1997) chamou de vontade de memória. É esta vontade que responde pela transformação do documento - no caso, o Palácio do Catete - em um lugar de memória, pois, na sua ausência, ele teria permanecido como um lugar de história.

É essa memória que o presente trabalho buscou focalizar, através da representação de Getúlio Vargas pelo conjunto de pessoas que revisitou a sua história, como cristalizada sob a forma de uma exposição comemorativa do cinqüentenário da sua morte e ambientada no mesmo lugar onde muitos dos principais episódios daquela trajetória e o seu próprio desfecho ocorreram, o antigo Palácio do Catete.

\section{Getúlio Vargas e o Palácio do Catete, um lugar de memória}

Segundo Nora (1997), três dimensões contribuem, simultaneamente e em diferentes graus, para caracterizar um lugar de memória. A dimensão material se refere ao espaço topográfico, monumental, arquitetural, ou à sua condição de objeto concreto (um quadro, um livro, etc); a dimensão funcional, à tarefa que ele cumpre de preservar um fato; a dimensão simbólica, aos significados que são construídos em torno dele de acordo com os valores, crenças e representações das pessoas. Em tal lugar, investido de intenções de lembranças que remetem a outras épocas, há um sentimento de continuidade e uma materialização dos acontecimentos passados. Desta forma, diz o autor, a história é incorporada pela memória e esta reconstrói a primeira.

O Palácio do Catete foi construído pelo Barão de Nova Friburgo em 1860 e passou, já nos primeiros anos da República (1894), a abrigar a sede do poder executivo, tendo sido palco dos principais acontecimentos da nossa história republicana até a transferência da capital federal para Brasília, em 1960, quando foi transformado em Museu da República. A entrada e a fachada frontal do Palácio dão diretamente para a movimentada Rua do Catete, que, embora hoje decadente, já foi um logradouro valorizado na cidade do Rio de Janeiro. Há relatos de que o presidente podia ser visto nas janelas e freqüentemente se dirigia ou acenava aos passantes. O Palácio fazia parte do cotidiano da população e esse clima de intimidade persiste até hoje, aumentado talvez por incluir agora um museu de portas abertas para a rua, um restaurante, um cinema, uma livraria e amplos jardins onde há sempre pessoas passeando, principalmente idosos, e crianças brincando.

Além das características materiais que privilegiam o Palácio do Catete como um marco concreto da memória histórica do país, outros fatores contribuem para a sua constituição em um lugar de memória indissociavelmente ligado à imagem de Getulio Vargas. Em primeiro lugar, Vargas foi o governante que por maior período contínuo de tempo ocupou o Catete - de 1930 a 1945 - e o único que a ele retornou, como quem volta à própria casa, para aí permanecer pelo resto da vida, de 1951 a 1954. Em segundo lugar, Vargas não deixou o Palácio por término do mandato presidencial, mas morto, sob circunstâncias dramáticas, que produziram intensa comoção popular e marcaram o fim de uma fase extremamente conturbada da vida política nacional. Em terceiro lugar, longe de ensejar o término do mito de Vargas, cuidadosamente construído durante o Estado Novo - período de 1937 a 1945, durante o qual o Congresso esteve fechado e Getúlio exerceu ditatorialmente o governo do país -, o suicídio veio a revigorá-lo e conferir-lhe, pelas freqüentes rememorações do episódio, um grau de permanência que o faz chegar até aos dias de hoje.

O esforço de rememoração sistemática foi mais uma vez produzido, quando do cinqüentenário da morte de Vargas, sob a forma da exposição Getúlio, Presidente do Brasil que o Museu da República manteve, no Palácio do Catete, por cinco meses a partir de 24 de agosto de 2004. O plano da exposição consistia em retratar as múltiplas faces dos governos Vargas, sob diferentes formas de linguagem, que incluíam um núcleo histórico, acrescido de representações artísticas e cenográficas. $\mathrm{O}$ visitante era levado a percorrer uma seqüência de espaços nos quais os rituais de poder, a construção da nova ordem econômica e social do país, o mito Vargas e suas representações, além das oposições e tensões desse período, eram apresentados através de fotos, objetos e documentos. Grandes painéis com cenas de eventos festivos, com a presença maciça de trabalhadores, davam o testemunho da participação popular na trajetória do estadista. O clima da reunião ministerial na noite que precedera o suicídio de Vargas aparecia recriado no próprio salão nobre do Palácio onde ela de fato ocorrera, trazendo à imaginação a dramaticidade da crise política e da decisão pessoal do presidente em se matar na qual ela culminaria. Eram exibidas ainda imagens do cortejo fúnebre, do laudo pericial da morte do presidente e do original da sua carta-testamento. Na última parte da mostra, o visitante era envolvido por uma atmosfera de luto, através da reprodução nas paredes das assinaturas do livro de presença do velório e da execução da música Noite no Catete, que o acompanhava até 
a ante-sala do quarto de Getúlio. Lá se encontravam expostos o paletó do pijama, a bala e o revólver usados no suicídio. No quarto, que apresentava a aparência de não ter sido tocado desde então, a iluminação em penumbra sugeria a solidão e amargura do presidente quando da consumação do ato.

\section{A representação de Getúlio Vargas, no Catete, cinqüenta anos depois}

O conjunto de representações sociais que configura o estado atual da memória de Getúlio Vargas foi objeto de uma investigação empírica junto à parcela da população brasileira que espontaneamente buscou reavivá-la em si própria - ou, em alguns casos, começar a construí-la -, através da ambientação histórica proporcionada pela exposição do cinqüentenário. Tratar-se-ia, por certo, de uma amostra enviesada, se o próprio viés - a procura ativa por um lugar de memória e o propósito de se deixar por ele embeber - não fosse uma característica definidora da memória histórica que se queria investigar. Em outras palavras, a pesquisa teve como objetivo descrever e comparar as representações de Getúlio por parte daquelas pessoas que se preocupavam em atualizá-las pelo confronto construtivo da sua própria memória com a história documental. Ressalve-se apenas que, no caso das crianças e adolescentes que visitaram a exposição, o propósito de construção da memória histórica não teve uma origem pessoal, mas sim institucional, por iniciativa das escolas que os levaram ao Museu.

\section{Método}

Durante o período de 19 de outubro a 7 de novembro de 2004, foram aplicados 410 questionários aos visitantes da exposição. Destes, 202 foram aplicados a pessoas que estavam entrando no Museu e 208 a pessoas que estavam saindo dele, por se supor que a exposição às informações do evento seria uma variável relevante para a atualização das memórias e dos julgamentos representacionais da figura histórica de Vargas.

O conjunto de sujeitos entrevistados ficou constituído por $32 \%$ de pessoas que tinham até 25 anos de idade, $27 \%$ com idades entre 26 e 40 anos e $41 \%$ com mais de 40 anos. Cabe observar que uma quarta parte desta última faixa etária (45 sujeitos) era de pessoas com mais de 60 anos de idade e que, portanto, tinham sido testemunhas do fim dramático do segundo governo Vargas.

Quanto à escolaridade, $16 \%$ dos sujeitos possuíam o nível fundamental, concluído ou não, $20 \%$ cursavam o nível médio ou o tinham concluído, 47\% tinham o nível superior ou o estavam cursando, além de $17 \%$ que haviam alcançado a pós-graduação. $\mathrm{O}$ fato de que quase duas terças partes dos entrevistados tivessem a formação universitária não surpreende nem compromete os resultados da pesquisa, visto que corresponde a um recorte óbvio da fração populacional que mais se ocupa da atualização da memória histórica nacional.

No que se refere à orientação política, 29\% dos sujeitos se declararam de direita ou centro-direita, enquanto $45 \%$ se disseram de esquerda ou centro-esquerda, além de $26 \%$ sem definição política. Descontando-se a possibilidade de que, como não havia a alternativa de resposta "centro" tout court, possa ter parecido mais politicamente correto a muitos sujeitos declarar-se de esquerda, convém-se que, de um modo geral, é no âmbito desta que um "dever de memória" tem sido mais consistentemente cultivado, não importando com que face os fatos acabem por se mostrar. À direita, ao contrário, parece tradicionalmente mais caro o argumento da "necessidade de esquecimento" de culpas e responsabilidades.

O questionário, com sete perguntas fechadas e cinco abertas, em uma única folha, como a situação de coleta expedita o exigia, foi adaptado a partir de um instrumento mais extenso desenvolvido anteriormente para uma tese de doutorado (Naiff, 2005). Dentre as questões abertas, incluiu-se uma tarefa de evocação livre ante o termo indutor "Getúlio Vargas". Dentre as questões fechadas, incluíram-se as caracterizações sócio-demográficas que acabam de ser resenhadas. As demais perguntas fechadas e as abertas solicitavam julgamentos quanto a coisas boas e ruins feitas por Getúlio, à lembrança de pessoas que o apoiaram ou lhe fizeram oposição, ao conhecimento das circunstâncias da sua morte, à indicação das fontes de suas lembranças e à preferência por uns ou outros dos epítetos comumente apostos a Vargas.

Os dados da evocação livre foram tratados com auxílio do programa EVOC (Vergès, 1999), a partir do cruzamento entre as freqüências e as ordens médias de evocação de cada palavra ou expressão lembrada. As respostas às perguntas fechadas e abertas, após a categorização das últimas, compuseram um banco de dados, a partir do qual foram construídas tabelas de distribuição de freqüências e comparações entre as contribuições relativas de diferentes variáveis - entrevista na entrada ou na saída da exposição, idade, escolaridade e orientação política para a produção dos resultados globais.

\section{Resultados}

Os resultados referentes à análise das evocações, apresentados e discutidos em Sá, Castro, Oliveira, Teixeira, Trezzi e Vetere (2005), evidenciaram cinco temas básicos - ditadura, leis trabalhistas (e trabalhadores), presidente (e grande presidente), suicídio e populismo - na composição privilegiada do núcleo central e da primeira periferia da representação social de Getúlio Vargas. Em resumo, concluiu-se que tal representação se organizava em torno de duas ordens de temas controversos: (1) o governo (primeiro) do "presidente" Vargas foi reconhecidamente uma "ditadura", mas ele não deixou de ter sido também um "grande presidente"; (2) o "populismo" constituiu um traço negativo marcante de Getúlio como governante, mas teve como saldo positivo as "leis trabalhistas", que fizeram justiça aos "trabalhadores". Finalmente, a imagem de Getúlio parecia indissociável do "suicídio" como um ato de vontade própria. Esta estrutura representacional sintetiza assim os eixos principais da memória histórica de Getúlio que foi trazida pelos visitantes ao e atualizada no - lugar de memória que é o Palácio do Catete.

Essa memória histórica básica de "Getúlio no Catete" é corroborada e desdobrada pelos resultados apresentados a seguir, que são relativos às respostas às demais perguntas do questionário pelo conjunto dos sujeitos entrevistados. Admite-se que, pela composição do grupo de participantes, tais resultados refletem principalmente as representações dos visitantes de maior 
idade, de maior nível de escolaridade e de orientação política de esquerda. As contribuições específicas à representação global pelos diferentes subconjuntos etários, de escolaridade e de orientação política serão objeto de uma próxima comunicação. Por outro lado, a condição das entrevistas terem sido realizadas na entrada ou na saída da exposição definirá dois subconjuntos de sujeitos, cujas representações serão comparadas, com vistas à inferência do papel da exposição na atualização da memória histórica de Getúlio e na confirmação do Palácio do Catete como um lugar de memória.

\section{As coisas boas e ruins que Getúlio fez}

Sem dúvida alguma, a memória social de Getúlio incorpora um saldo extremamente positivo de realizações louváveis como governante, como mostra a Tabela 1 . Mais de $70 \%$ dos visitantes, sem diferença estatisticamente significativa entre as condições de entrada e saída da exposição, declaram que Getúlio fez mais coisas boas do que ruins, enquanto apenas cerca de $10 \%$ acha que ele fez mais coisas ruins, uma proporção menor ainda do que os quase $15 \%$ que dizem que ele fez tanto coisas boas quanto ruins.

Tabela 1

Distribuição dos julgamentos dos visitantes do Museu da República quanto às coisas boas e às coisas ruins feitas por Getúlio Vargas. (Rio de Janeiro, 2004)

\begin{tabular}{|c|c|c|c|c|c|c|}
\hline \multirow{3}{*}{ Julgamentos } & \multicolumn{4}{|c|}{ Ocasião da entrevista } & \multirow{3}{*}{ Total } & \multirow{3}{*}{$\%$} \\
\hline & \multicolumn{2}{|c|}{ Entrada do Museu } & \multicolumn{2}{|c|}{ Saída do Museu } & & \\
\hline & Freqüência & $\%$ & Freqüência & $\%$ & & \\
\hline Mais coisas boas & 146 & 72,28 & 152 & 73,08 & 298 & 72,68 \\
\hline Mais coisas ruins & 21 & 10,40 & 17 & 8,17 & 38 & 9,27 \\
\hline Meio a meio & 30 & 14,85 & 27 & 12,98 & 57 & 13,90 \\
\hline Não sabe / Não se lembra & 4 & 1,98 & 6 & 2,88 & 10 & 2,44 \\
\hline Outra resposta & 1 & 0,50 & 6 & 2,88 & 7 & 1,71 \\
\hline Total & 202 & 100,00 & 208 & 100,00 & 410 & 100,00 \\
\hline
\end{tabular}

Dentre as coisas boas feitas por Getúlio, sobressai nitidamente, com mais de $40 \%$ do total de respostas, o conjunto "leis trabalhistas" e "benefícios genéricos para o povo", seguido pelo bloco "desenvolvimento", "industrialização" - com ênfase à "Companhia Siderúrgica Nacional" e à "Petrobrás" - e "modernização", com cerca de $25 \%$ das respostas. Por outro lado, dentre as coisas ruins, igual contraposição de mais de $40 \%$ das respostas é dada pelo conjunto "ditadura, autoritarismo", "ações contra o estado de direito", "repressão, prisões, tortura" e "censura, cerceamento de liberdades". Não obstante esse aparente equilíbrio ou convivência entre julgamentos opostos, já evidenciado na análise estrutural da representação, cabe observar que o número de lembranças espontâneas de coisas ruins correspondeu a não mais do que três quartos do número de lembranças de coisas boas, além do que, enquanto apenas 14\% dos sujeitos disseram não ter havido coisas boas ou delas não se lembrarem, mais do que o dobro deles, $31 \%$, declarou não ter havido coisas ruins ou delas não se lembrarem.

No que se refere às coisas ruins que Getúlio teria feito, um resultado interessante é que cerca de $10 \%$ das respostas, seja na entrada da exposição ou na saída, aludem a "simpatia pelo nazi-fascismo e submissão aos EUA", em conjunto com "perseguição aos comunistas e repúdio aos judeus". Tal resultado foi possivelmente influenciado pelo lançamento do filme Olga, de J. Monjardim, e pela reedição do livro (Morais, 2004) em que aquele se baseara - duas espécies de produtos culturais bastante eficazes na atualização da memória social -, que focalizavam a trajetória dramática de Olga Benário, alemã que militou no movimento comunista brasileiro, a ser relembrada mais adiante.

\section{Quem era a favor e quem era contra Getúlio}

A lembrança espontânea dos correligionários de Getúlio Vargas e dos personagens com os quais ele travou embates políticos traz à tona - acima do patamar de $5 \%$ do total de participantes - não mais do que dez nomes. Os mais lembrados - igualmente e por menos de um quarto da amostra - são justamente seus principais adversários, em duas épocas distintas: Luiz Carlos Prestes (1898-1990), o líder comunista com quem ele se confrontou durante o todo o primeiro governo, e Carlos Lacerda (1914-1977), o político que lhe fez ferrenha oposição durante o segundo governo. Uma primeira influência da exposição Getúlio, Presidente do Brasil pode ser aqui notada, pois, enquanto Lacerda era um pouco mais lembrado pelos visitantes na entrada, Prestes foi duas vezes mais lembrado na saída.

Seguem-se, na amostra global e sem maiores alterações de ordem entre a entrada e a saída, três figuras de apoio a Getúlio: o herdeiro político imediato, João Goulart, Jango (1918-1976), que viria a se tornar presidente da República em 1961 e seria deposto em 1964 pelo golpe que instituiu uma ditadura militar no país; o polêmico chefe da guarda palaciana, o "anjo negro" Gregório Fortunato (1900-1962), implicado no atentado à vida de Lacerda; e o último representante da chamada Era Vargas, Leonel Brizola (1922-2004), cuja memória foi certamente favorecida pela sua contínua atuação política até o falecimento recente.

Surge, em seguida, o nome de Olga Benário (1908-1942), um verdadeiro ícone das vítimas das coisas ruins que Getúlio teria feito. Militante comunista de origem alemã, Olga veio, em 1934, de Moscou para o Brasil, acompanhando Prestes, como 
responsável pela segurança deste durante a viagem, e tornou-se sua primeira mulher. Em 1936, foi presa e repatriada, grávida, para a Alemanha, onde teve sua filha e terminou executada pelo governo nazista.

Vêm ainda, lembrados por cerca de 5\% dos entrevistados, o fiel ministro Tancredo Neves (1910-1985), cuja lembrança de então possivelmente se soma à da sua atuação ao longo do Regime Militar (1964-1985), e Juscelino Kubitschek (1902-1976), o presidente que promoveu a construção da nova capital, Brasília, em 1960, e deu continuidade à pauta varguista de industrialização e modernização. Dignos de lembrança foram ainda o polêmico ministro Oswaldo Aranha (1894-1960), que, representando o supostamente anti-semita governo Vargas, teve atuação decisiva na aprovação pela ONU da criação do estado de Israel, e o historicamente execrado Filinto Müller (1900-1973), chefe da polícia política responsável pela violenta e cruel repressão durante o Estado Novo (1937-1945).

Abaixo desse patamar são ainda lembrados 17 nomes, dos quais, como ilustração, cabe citar três: um outro ditador, com quem se dizia Getúlio guardar grande afinidade, Adolf Hitler (1889-1945); a filha fiel e querida, Alzira Vargas do Amaral Peixoto (1914-1992); a vedete de teatro de revista e suposta amante secreta, Virgínia Lane (1920-).

\section{O lugar e as circunstâncias da morte de Getúlio}

Onde e como Getúlio Vargas morreu, circunstâncias que podem ser secundárias numa apreciação histórica do seu papel na definição dos destinos políticos e econômicos do país, bem como na determinação das condições sociais do seu povo, mostram-se cruciais na construção e atualização da sua memória histórica. O encerramento da trajetória de vida de Getúlio no Palácio do Catete é um marco concreto e tão importante dessa memória que faz com que tal trajetória seja comumente relembrada de trás para frente e quase inteiramente concentrada nesse lugar. A rigor, os participantes da pesquisa - à exceção de uma parte das crianças e adolescentes - não foram conhecer as circunstâncias da morte de Getúlio em sua visita à exposição, mas sim a visitaram para verem confirmado - possivelmente em detalhes mais vívidos aquilo de que já tinham uma lembrança antiga e consolidada.

De fato, as respostas de "suicídio" e "tiro" foram dadas por $97 \%$ dos entrevistados, sem diferenças estatisticamente significativas entre os abordados na entrada e na saída da exposição. Apenas, o número de respostas "suicídio" foi menor e o de respostas "tiro" maior entre os sujeitos de saída, porque a exposição enfatizava a forma como o suicídio ocorrera. Nesse mesmo sentido, respostas equivocadas de "assassinato" e "outras causas" caíram de já escassos $4 \%$ na entrada para menos da metade disso na saída.

Quanto ao local da morte de Getúlio, a Tabela 2 mostra que mais de dois terços dos sujeitos indicaram o Palácio do Catete, os quais, somados aos que possivelmente tinham isso como implícito e respondiam "em casa" ou explicitavam que ele morreu "no quarto", "na cama", perfazem mais de $90 \%$ da amostra global. Comparando as respostas dos entrevistados na entrada da exposição com as dos entrevistados na saída, verificase ainda uma diminuição no número dos que não sabiam ou não lembravam e um aumento no dos que explicitavam a casa, o quarto, a cama.

Tabela 2

Distribuição das respostas dos visitantes do Museu da República quanto ao local da morte de Getúlio Vargas. (Rio de Janeiro, 2004)

\begin{tabular}{|c|c|c|c|c|c|c|}
\hline \multirow{3}{*}{ Respostas } & \multicolumn{4}{|c|}{ Ocasião da entrevista } & \multirow{3}{*}{ Total } & \multirow{3}{*}{$\%$} \\
\hline & \multicolumn{2}{|c|}{ Entrada do Museu } & \multicolumn{2}{|c|}{ Saída do Museu } & & \\
\hline & Freqüência & $\%$ & Freqüência & $\%$ & & \\
\hline Palácio do Catete & 133 & 68,91 & 136 & 67,00 & 269 & 67,93 \\
\hline Em casa / Na sua cama / No quarto & 41 & 21,24 & 54 & 26,60 & 95 & 23,99 \\
\hline Não sabe /Não lembra & 16 & 8,29 & 11 & 5,42 & 27 & 6,82 \\
\hline Outras & 3 & 1,55 & 2 & 0,99 & 5 & 1,26 \\
\hline Não sabia como Vargas morreu (questão anterior) & 9 & -- & 5 & -- & 14 & \\
\hline Total & 202 & 100,00 & 208 & 100,00 & 410 & 100,00 \\
\hline
\end{tabular}

\section{As fontes da memória histórica de Getúlio Vargas}

Como mostra a Tabela 3, as fontes documentais privilegiadas da memória de Getúlio são a própria história contada nos manuais escolares, com 54\% das indicações, e o noticiário político em jornais e na televisão, com quase $18 \%$. Sá (2005) assim comenta a importância dessas duas fontes para a constituição de memórias históricas documentais, uma das subcategorias - a par das memórias orais - em que ele divide as memórias históricas:

Nesse sentido, além dos vestígios históricos, dos monumentos, dos conteúdos expostos nos museus e dos documentos escritos que compõem os acervos de bibliotecas e de arquivos públicos e privados, situam-se nessa subcategoria duas espécies de recursos de uso mais amplamente socializado: (1) de forma já há muito consolidada, os manuais escolares de história; (2) de forma continuamente atualizada e, em grande parte, através de imagens, os registros proporcionados pela comunicação de massa, em especial pela televisão. Os primeiros têm sido responsáveis pela transformação de fatos não vividos em conteúdos de memórias comuns, notadamente geracionais, e coletivas, pois, como argumenta M. Ferro (1990), "a história tal como nos foi contada quando éramos crianças deixa sua marca em nós para toda a vida" (p. 9).

Seguem-se, na ordem de atribuição pelos participantes, uma fonte oral - conversas na família e com amigos -, sem a qual, segundo autores desde Halbwachs (por exemplo: Fentress 
\& Wickham, 1994; Jedlowski, 2000, 2001), não se constituem autênticas memórias coletivas, e uma fonte documental - a própria exposição Getúlio, Presidente do Brasil - constituinte do lugar de memória Palácio do Catete.

O papel da exposição na atualização da memória histórica de Getúlio parece bem demonstrado pela diferença estatisticamente significativa $(p<0,05)$ registrada entre as respostas de entrada e de saída. De fato, a indicação desta fonte pelos sujeitos entrevistados na saída do Museu é proporcionalmente nove vezes maior do que pelos entrevistados na entrada, isto ocorrendo em relativo detrimento da atribuição ao estudo da história, à mídia e às interações face-a-face.

Tabela 3

Distribuição das fontes de conhecimento dos visitantes do Museu da República sobre a vida e a morte Getúlio Vargas. (Rio de Janeiro, 2004)

\begin{tabular}{|c|c|c|c|c|c|c|}
\hline \multirow{3}{*}{ Fontes de conhecimento } & \multicolumn{4}{|c|}{ Ocasião da entrevista } & \multirow{3}{*}{ Total } & \multirow{3}{*}{$\%$} \\
\hline & \multicolumn{2}{|c|}{ Entrada do Museu } & \multicolumn{2}{|c|}{ Saída do Museu } & & \\
\hline & Freqüência & $\%$ & Freqüência & $\%$ & & \\
\hline Do estudo da história na escola & 159 & 58,03 & 162 & 51,10 & 321 & 54,31 \\
\hline Do noticiário político em jornais ou na televisão & 57 & 20,80 & 47 & 14,83 & 104 & 17,60 \\
\hline De conversas na família e com amigos & 48 & 17,52 & 47 & 14,83 & 95 & 16,07 \\
\hline Da exposição do Museu da República & 6 & 2,19 & 57 & 17,98 & 63 & 10,66 \\
\hline Outras & 3 & 1,09 & 4 & 1,26 & 7 & 1,18 \\
\hline Sem resposta & 1 & 0,36 & - & - & 1 & 0,17 \\
\hline Total & 274 & 100,00 & 317 & 100,00 & 591 & 100,00 \\
\hline
\end{tabular}

Nota: os participantes puderam indicar mais de uma fonte de conhecimento.

Getúlio Vargas: "pai dos pobres", ditador ou estadista?

Os últimos dados obtidos referem-se ao grau em que epítetos ou rótulos diversos que têm sido associados à imagem de Getúlio Vargas foram incorporados à sua memória histórica. Os resultados praticamente reproduzem aqueles relativos às coisas boas e ruins feitas por ele, ou seja, muito mais coisas boas do que ruins. E, da mesma forma, não há diferenças estatisticamente significativas entre as respostas coletadas na saída do Museu e aquelas que haviam sido coletadas na entrada.

De fato, verifica-se que, na Tabela 4, a soma das respostas de endosso aos epítetos pai dos pobres e maior estadista do Brasil corresponde a dois terços do total de manifestações. Uma quarta parte destas, entretanto, não deixa de fazer coro ao rótulo de ditador autoritário e repressor. Inexpressivas são a concordância com a imagem de político desleal e a indicação de que nenhum dos rótulos propostos - dois positivos e dois negativos - se aplica a Getúlio.

Tabela 4

Distribuição das respostas dos visitantes do Museu da República quanto aos epítetos que mais se aplicam a Getúlio Vargas. (Rio de Janeiro, 2004)

\begin{tabular}{|c|c|c|c|c|c|c|}
\hline \multirow{3}{*}{ Epítetos } & \multicolumn{4}{|c|}{ Ocasião da entrevista } & \multirow{3}{*}{ Total } & \multirow{3}{*}{$\%$} \\
\hline & \multicolumn{2}{|c|}{ Entrada do Museu } & \multicolumn{2}{|c|}{ Saída do Museu } & & \\
\hline & Freqüência & $\%$ & Freqüência & $\%$ & & \\
\hline Pai dos pobres & 88 & 26,43 & 113 & 34,14 & 201 & 30,27 \\
\hline Ditador autoritário e repressor & 95 & 28,53 & 88 & 26,59 & 183 & 27,56 \\
\hline Maior estadista do Brasil & 137 & 41,14 & 119 & 35,95 & 256 & 38,55 \\
\hline Político desleal & 8 & 2,40 & 8 & 2,42 & 16 & 2,41 \\
\hline Nenhum & 5 & 1,50 & 3 & 0,91 & 8 & 1,20 \\
\hline Total & 333 & 100,00 & 331 & 100,00 & 664 & 100,00 \\
\hline
\end{tabular}

Nota. Os participantes puderam indicar mais de um epíteto como aplicável.

\section{Conclusão}

A memória histórica que a população brasileira guarda de Getúlio Vargas e de seus governos encontra-se intrinsecamente associada ao Palácio do Catete. É tal associação que, constantemente reforçada e investida de uma intensa vontade de memória, nos termos de Nora (1997), se configura contemporaneamente como um lugar de memória. A exposição Getúlio, Presidente do Brasil, ambientada no Palácio e visitada por 160.000 pessoas, reitera e consolida definitivamente a associação Vargas-Catete como um lugar em que a história de cinqüenta anos atrás se transforma numa memória viva.

O presente trabalho procurou complementar a descrição anteriormente feita (Sá, Castro, Oliveira, Teixeira, Trezzi, \& Vetere, 2005), em termos temáticos e estruturais, da representação social de Getúlio que os visitantes da exposição traziam e aí atualizavam ou, em alguns casos, começavam a construir. Uma primeira e nítida conclusão é que os novos resultados corroboram amplamente a natureza polêmica e controvertida de que se revestia aquela representação.

Por outro lado, como uma segunda conclusão importante, os presentes resultados fazem a balança pender decisivamente 
para a persistência de uma memória muito mais favorável do que desfavorável à imagem de Getúlio Vargas. De fato, não apenas predomina um julgamento global de que Getúlio teria feito mais coisas boas do que ruins, mas também, quando solicitados a nomear espontaneamente tanto umas quanto as outras, os entrevistados apresentam um número bastante maior de lembranças para as primeiras - leis trabalhistas, industrialização, modernização, nacionalismo - do que para as segundas ditadura, repressão, censura, simpatia pelo nazi-fascismo e perseguição aos comunistas.

Nesse mesmo sentido, ao se eleger os rótulos sintéticos que mais se aplicariam a Getúlio, o preferido é maior estadista do Brasil. Enquanto isso, pai dos pobres e ditador autoritário se confrontam com números semelhantes de respostas, mas ambos se associando igualmente à imagem de estadista. É oportuno lembrar que, na configuração estrutural inicialmente levantada, os temas ditadura e presidente, grande presidente eram dotados de graus semelhantes de centralidade representacional. A rigor, nem sempre, ao longo da história, as condições de ditador e de estadista se excluíram mutuamente, sendo sua atual incompatibilidade uma conquista da evolução do pensamento democrático. Assim, a memória histórica aqui focalizada parece guardar algo do espírito da época e não submeter inteiramente a imagem de Getúlio aos juízos característicos do presente.

A natureza controvertida da memória de Getúlio recebeu um desdobramento peculiar por meio das pessoas que foram lembradas em associação a ele, ou seja, tanto os amigos e aliados fiéis - Jango, Tancredo, Brizola, a filha Alzira, a amante Virgínia - quanto os inimigos e opositores implacáveis - Prestes, Lacerda -, as vítimas - Olga - e os principais responsáveis pela face mais negativa da sua imagem - o chefe de polícia Filinto, o guarda-costas Fortunato. É possível especular que todos esses personagens são eles próprios lembrados hoje em dia, alguns mais e outros menos, em função das relações que tiveram com a figura central da Era Vargas, que, segundo alguns se estende até hoje.

O lugar e as circunstâncias da morte de Getúlio constituem a porção mais fielmente retida da sua trajetória política e a responsável fundamental pela transformação do Palácio do Catete em um lugar de memória. Os 45 respondentes da pesquisa que tinham mais de 60 anos mostraram guardar desse episódio memórias flash (De Rosa, 2005, para uma síntese) bastante vívidas, que serão objeto de uma comunicação futura e dão conta da sua dramaticidade, da comoção popular e da inflexão que ensejou no curso dos acontecimentos políticos nacionais. Muito dessa memória é, não obstante, incorporada pelos visitantes mais jovens por força exclusiva da vontade de memória investida sobre o Museu da República, da qual a exposição Getúlio, Presidente do Brasil constituiu uma instância fundamental. Praticamente todos os visitantes da exposição sabiam onde e como o suicídio ocorrera, mas, mais do que saber, eles queriam e puderam se fazer presentes à cena e ao clima originais, acrescentando assim ao simples conhecimento a emoção que faz uma memória.

Finalmente, dentre as fontes explicitadas da memória histórica de Getúlio, o estudo da história surge como a principal. De fato, conhecer a história é a condição básica para que se possa constituir uma memória de acontecimentos que as pessoas não tenham chegado a testemunhar pessoalmente ou a ter ouvido falar deles sistematicamente em seus círculos próximos. A memória histórica de acontecimentos remotos não é uma propriedade misteriosa que possa impregnar determinados conjuntos sociais, mas é sim construída - ou, mais freqüentemente, atualizada a partir do que se sabe sobre o passado. A diferença básica é que um conhecimento pode ser adquirido e não se transformar numa memória, pois isto só ocorre quando tal conhecimento é cultivado, seja por indivíduos isolados, uns em relação aos outros - transformando-se então em memórias comuns - seja por conjuntos de indivíduos em variadas formas e intensidades de relações - constituindo-se em memórias coletivas. Embora uma memória histórica - documental ou oral-seja tipicamente uma memória coletiva, ela pode ser continuamente alimentada por memórias comuns que sejam submetidas à influência de fatores socialmente agregadores, como os lugares de memória.

\section{Agradecimentos}

Os autores agradecem o apoio do CNPq e da FAPERJ.

\section{Referências}

Bartlett, F. C. (1995). Remembering: a study in experimental and social psychology. Cambridge: Cambridge University Press.

Bosi, E. (1979). Memória e sociedade: lembranças de velhos. São Paulo: Queiroz.

Castro, R. V. (2005). O quarto de Getúlio: representações e memória na política brasileira. In C. P. Sá (Org.), Memória, imaginário e representações sociais (pp. 199-208). Rio de Janeiro: Museu da República.

Castro, R. V., Sá, C. P., Möller, R. C., \& Bezerra, F. C. C. (2005). O esquecimento social na representação do Regime Militar por jovens na cidade do Rio de Janeiro. IV Jornada Internacional e II Conferência Brasileira sobre Representações Sociais. Textos completos (pp. 1298-1314). João Pessoa: Editora da Universidade Federal da Paraíba.

De Rosa, A. S. (2005). O impacto das imagens e o compartilhamento social das emoções na construção da memória social: uma chocante memória flash de massa do 11 de setembro até a guerra do Iraque. In C. P. Sá (Org.), Memória, imaginário e representações sociais (pp. 121-164). Rio de Janeiro: Museu da República.

Fentress, J., \& Wickham, C. (1994). Memória social. Lisboa: Teorema.

Ferro, M. (1990). Cómo se cuenta la historia a los niños del mundo entero. México: Fondo de Cultura Económica.

Halbwachs, M. (1994). Les cadres sociaux de la mémoire. Paris: Albin Michel. (obra originalmente publicada em 1925)

Halbwachs, M. (1997). La mémoire collective. Paris: Albin Michel. (obra originalmente publicada em 1950)

Jedlowski, P. (2000). La sociologia y la memoria colectiva. In A. Rosa, G. Bellelli, \& D. Bakhurst (Orgs.), Memoria colectiva e identidad nacional (pp. 123-134). Madrid: Biblioteca Nueva.

Jedlowski, P. (2001). Memory and sociology: themes and issues. Time \& Society, 10(1), 29-44.

Le Goff, J. (1988). Histoire et mémoire. Paris: Gallimard.

Möller, R. C., Sá, C. P., \& Bezerra, F. C. C. (2004). Representações sociais vivas do descobrimento do Brasil: a memória social actualizada de brasileiros e portugueses. Psicologia, Lisboa, 17, 401-413.

Morais, F. (2004). Olga. São Paulo: Companhia das Letras.

Naiff, D. G. M. (2005). A memória social dos governos Vargas: um estudo comparativo entre duas gerações no Rio de Janeiro. Tese de doutorado nãopublicada, Universidade do Estado do Rio de Janeiro, Rio de Janeiro. 
Naiff, D. G. M., Sá, C. P., \& Möller, R. C. (2004). O descobrimento do Brasil na imprensa diária brasileira: a actualização gradativa da memória social. Psicologia, Lisboa, 17, 345-357.

Nora, P. (1997). Entre mémoire et histoire: la problématique des lieux. In P. Nora (Org.), Les lieux de mémoire (pp. 23-43). Paris: Gallimard.

Oliveira, D. C., Lewin, M. C., \& Sá, C. P. (2004). A memória primordial do descobrimento do Brasil: análise dos manuais brasileiros de história. Psicologia, Lisboa, 17, 301-319.

Sá, C. P. (2005). As memórias da memória social. In C. P. Sá (Org.), Memória imaginário e representações sociais (pp. 63-86). Rio de Janeiro: Museu da República.

Sá, C. P. (2007). Sobre o campo de estudo da memória social: uma perspectiva psicossocial. Psicologia: Reflexão \& Crítica, 20(2), 289-294.

Sá, C. P. (no prelo). Les défis d'une psychologie sociale de la mémoire. Maison des Sciences de l'Homme.

Sá, C. P. \& Castro, P. (Orgs.). (2005). Memórias do descobrimento do Brasil. Rio de Janeiro: Museu da República.

Sá, C. P., Castro, R. V., Oliveira, D. C., Teixeira, C. G. M., Trezzi, S., \& Carvalho, R. V. C. (2005). As representações sociais de Getúlio Vargas por diferentes conjuntos de visitantes do Palácio do Catete. IV Jornada Internacional e II
Conferência Brasileira sobre Representações Sociais. Textos Completos (pp. 1140-1154). João Pessoa: Editora da Universidade Federal da Paraíba.

Sá, C. P., Castro, R. V., Oliveira, D. C., Teixeira, C. G. M., Trezzi, S., \& Vetere, R. (2005). A representação social de Getúlio Vargas e o Palácio do Catete: um lugar de memória. IV Jornada Internacional e II Conferência Brasileira sobre Representações Sociais. Textos Completos (pp. 1124-1139). João Pessoa: Editora da Universidade Federal da Paraíba.

Sá, C. P., \& Oliveira, D. C. (2002). Sur la mémoire sociale de la découverte du Brésil. In S. Laurens \& N. Roussiau (Orgs.), La mémoire sociale-identités et représentations sociales (pp. 107-117). Rennes: Presses Universitaires de Rennes.

Sá, C. P., Oliveira, D. C., \& Prado, L. A. (2004). As memórias colectivas do descobrimento do Brasil: imagens comuns e juízos diferenciados nas populações portuguesa e brasileira. Psicologia, Lisboa, 17, 297-315.

Sá, C. P., \& Vala, J. (2000). Representaciones sociales del pasado: los “descubrimientos" de América y de Brasil. In A. Rosa, G. Bellelli \& D. Bakhurst (Orgs.), Memoria colectiva e identidad nacional (pp. 429-449). Madrid: Biblioteca Nueva.

Vergès, P. (1999). EVOC - Ensemble de programmes permettant l'analyse des évocations: manuel version 2. Aix-en-Provence: LAMES.

${ }^{1}$ Participaram da coleta e da tabulação dos dados: Carla Geraldo de Moraes Teixeira, doutoranda do PPGPS/UERJ; Renata Vetere e Rafael Vera Cruz de Carvalho, alunos de graduação em Psicologia da UERJ e bolsistas de Iniciação Científica / CNPq.

Celso Pereira de Sá, doutor em Psicologia pela Fundação Getúlio Vargas (FGV-RJ), é professor titular de Psicologia Social na Universidade do Estado do Rio de Janeiro. Endereço para correspondência: Rua General Ribeiro da Costa, 178, B1.1/1201; Rio de Janeiro, RJ; CEP: 22010-050. Telefax: (21) 2587-7284. E-mail: sa.celso@gmail.com

Ricardo Vieiralves de Castro, doutor em Comunicação pela Universidade Federal do Rio de Janeiro (UFRJ), é professor adjunto na Universidade do Estado do Rio de Janeiro. E-mail: ricardo.vieiralves@gmail.com Renato Cesar Möller, doutor em Psicologia Social pela Universidade do Estado do Rio de Janeiro (UERJ), é professor na Faculdade Salesiana Maria Auxiliadora. E-mail: renatomoller@uol.com.br Juliana Aieta Perez, graduada em Estatística pela Universidade do Estado do Rio de Janeiro (UER), é bolsista de apoio técnico do CNPq na Universidade do Estado do Rio de Janeiro. E-mail: julirjbr@yahoo.com.br 